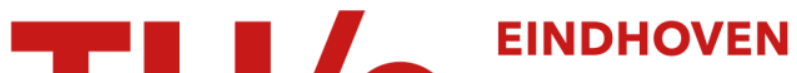 UNIVERSITY OF TECHNOLOGY
}

\section{Simultaneous two-state lasing in quantum-dot lasers}

\section{Citation for published version (APA):}

Markus, A., Chen, J. X., Paranthoën, C., Fiore, A., Platz, C., \& Gauthier-Lafaye, O. (2003). Simultaneous twostate lasing in quantum-dot lasers. Applied Physics Letters, 82(12), 1818-1820.

https://doi.org/10.1063/1.1563742

DOI:

10.1063/1.1563742

Document status and date:

Published: 01/01/2003

\section{Document Version:}

Publisher's PDF, also known as Version of Record (includes final page, issue and volume numbers)

\section{Please check the document version of this publication:}

- A submitted manuscript is the version of the article upon submission and before peer-review. There can be important differences between the submitted version and the official published version of record. People interested in the research are advised to contact the author for the final version of the publication, or visit the $\mathrm{DOI}$ to the publisher's website.

- The final author version and the galley proof are versions of the publication after peer review.

- The final published version features the final layout of the paper including the volume, issue and page numbers.

Link to publication

\section{General rights}

Copyright and moral rights for the publications made accessible in the public portal are retained by the authors and/or other copyright owners and it is a condition of accessing publications that users recognise and abide by the legal requirements associated with these rights.

- Users may download and print one copy of any publication from the public portal for the purpose of private study or research.

- You may not further distribute the material or use it for any profit-making activity or commercial gain

- You may freely distribute the URL identifying the publication in the public portal.

If the publication is distributed under the terms of Article 25fa of the Dutch Copyright Act, indicated by the "Taverne" license above, please follow below link for the End User Agreement:

www.tue.nl/taverne

Take down policy

If you believe that this document breaches copyright please contact us at:

openaccess@tue.nl

providing details and we will investigate your claim. 


\title{
Simultaneous two-state lasing in quantum-dot lasers
}

\author{
A. Markus, ${ }^{\text {a) }}$ J. X. Chen, ${ }^{\text {b) }}$ C. Paranthoën, and A. Fiore ${ }^{\text {c) }}$ \\ Institute of Quantum Electronics and Photonics, Ecole Polytechnique Fédérale de Lausanne EPFL, \\ CH-1015 Lausanne, Switzerland \\ C. Platz \\ Laboratoire de Physique des Solides, INSA de Renńes, 20 Avenue des Buttes de Coesmes, 35043 Rennes \\ Cedex, France \\ O. Gauthier-Lafaye \\ Opto +, Alcatel CIT, Route de Nozay, 91461 Marcoussis Cedex, France
}

(Received 12 December 2002; accepted 29 January 2003)

\begin{abstract}
We demonstrate simultaneous lasing at two well-separated wavelengths in self-assembled InAs quantum-dot lasers, via ground-state (GS) and excited-state (ES) transitions. This effect is reproducible and strongly depends on the cavity length. By a master-equation model, we attribute it to incomplete clamping of the ES population at the GS threshold. (C) 2003 American Institute of Physics. [DOI: 10.1063/1.1563742]
\end{abstract}

Self-assembled quantum dots (QDs) represent a distributed ensemble of zero-dimensional structures with a nearsingular density of states. Implemented as the active medium in a diode laser, their unique properties lead to improved characteristics compared to bulk or quantum-well (QW) devices. ${ }^{1}$ In the recent past, ultralow threshold current densities, ${ }^{2}$ combined with decreased temperature sensitivity, ${ }^{3,4}$ high modulation bandwidth, ${ }^{4}$ and low chirp, ${ }^{5}$ were reported-as predicted many years ago. The differential efficiency of these devices is, to date, lower than expected.

In this letter, we show that carrier population does not completely clamp at threshold, as evidenced by the appearance of a second lasing line at high bias, corresponding to the excited-state (ES) transition. This behavior is related to the finite intraband relaxation time (the so-called "phonon-bottleneck" ${ }^{6,7}$ ) combined with a limited density of states, and has important consequences for the ground-state (GS) lasing efficiency. First, we present experimental evidence of the dual-wavelength operation for lasers with two different cavity lengths under various conditions. We then employ a theoretical model to explain and to analyze these results.

The lasers used in our experiments were grown by molecular-beam epitaxy. ${ }^{8,9}$ The active region is formed by three layers of self-assembled InAs QDs, which are covered by a 5-nm $\operatorname{In}_{0.15} \mathrm{Ga}_{0.85}$ As QW and separated from each other by a $40-\mathrm{nm}$ GaAs spacer layer. The areal dot density of our lens-shaped QDs is $3 \times 10^{10} \mathrm{~cm}^{-2}$. The laser cavity is clad by $1.5 \mu \mathrm{m}$ of $\mathrm{Al}_{0.7} \mathrm{Ga}_{0.3} \mathrm{As}$, which is $n$-doped on the substrate side and $p$-doped on the top side. Our devices are ridgewaveguide lasers with 8 - and $15-\mu \mathrm{m}$ widths. Both facets are as cleaved.

Typical room-temperature emission spectra in pulsed

\footnotetext{
${ }^{a)}$ Electronic mail: alexander.markus@epfl.ch

${ }^{b}$ Present address: Bell Laboratories, Lucent Technologies, Inc., 600 Mountain Ave., Murray Hill, NJ 07974.

${ }^{c}$ Permanent address: Institute of Photonics and Nanotechnology, CNR, Via del Cineto Romano 42, 00156 Roma, Italy.
}

mode (1- $\mu$ s pulses, $10 \%$ duty cycle) at various cavity lengths are shown in Fig. 1. In a short stripe of length $l=400 \mu \mathrm{m}$, lasing is inhibited, and the spontaneous emission spectrum at high current densities can be measured (Fig. 1, bottom lines). Energy-state filling is evident with increasing injection current. GS and ES emissions are peaked at 1288 and $1194 \mathrm{~nm}$, respectively. Both peaks in the electroluminescence (EL) lines are relatively narrow $(50-70 \mathrm{~nm})$ and are well resolved. The saturated intensity of the ES line is about twice the GS intensity, corresponding to the double degeneracy of the ES. At a cavity length of $1000 \mu \mathrm{m}$ (Fig. 1, middle lines), lasing occurs via the ES transition, with a threshold current density of $J=710 \mathrm{~A} / \mathrm{cm}^{2}$. The single lasing line at threshold is located at $1195 \mathrm{~nm}$. Increasing the cavity length to $2000 \mu \mathrm{m}$ (Fig. 1, upper lines) leads to lasing via the GS transition with

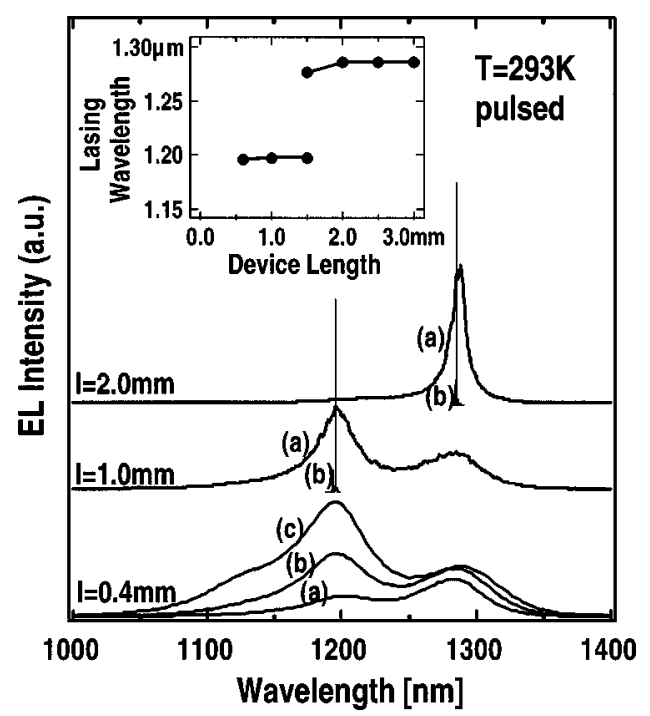

FIG. 1. Room-temperature emission spectra at various cavity lengths $l$. The lines on the bottom show spontaneous emission spectra for $l=0.4 \mathrm{~mm}$ at current densities of (a) $220 \mathrm{~A} / \mathrm{cm}^{2}$, (b) $390 \mathrm{~A} / \mathrm{cm}^{2}$, and (c) $710 \mathrm{~A} / \mathrm{cm}^{2}$. The upper lines are EL spectra (a) slightly below and (b) slightly above threshold for $l=1.0 \mathrm{~mm}$ and $l=2.0 \mathrm{~mm}$. The inset depicts the dependence of the lasing wavelength at threshold on the cavity length. 


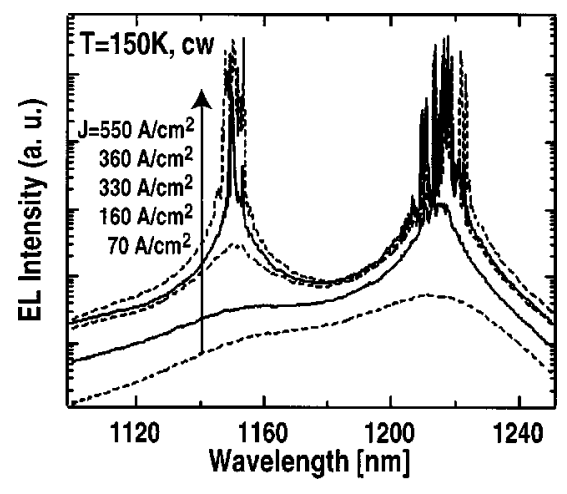

FIG. 2. EL spectra in logarithmic scale of a $l=1500-\mu \mathrm{m}$-long device at $\mathrm{cw}$ operation and at $T=150 \mathrm{~K}$ at various current densities $J$.

a lasing line at $1284 \mathrm{~nm}$ at threshold $\left(J=210 \mathrm{~A} / \mathrm{cm}^{2}\right)$. The dependence of the lasing wavelength at threshold on the cavity length is shown in the inset of Fig. 1. For devices shorter than $1500 \mu \mathrm{m}$, the gain of the GS transition is too small to compensate for the total loss, and lasing proceeds via the ES transition with a steplike switch of the lasing wavelength, as already reported. ${ }^{10,11}$ At the critical cavity length of 1500 $\mu \mathrm{m}$, we observed that lasing just above threshold ( $J$ $=580 \mathrm{~A} / \mathrm{cm}^{2}$ ) occurs at both state transitions, with lasing modes located at 1275 and $1195 \mathrm{~nm}$.

We investigated the spectral behavior of lasers with cavity length ranging from 1500 to $2000 \mu \mathrm{m}$. In all samples, we observe the appearance of a second lasing line at the ES energy at currents well above threshold. To show that double-state lasing indeed occurs simultaneously and to rule out the possibility of wavelength switching from the GS to the ES transition during the pulse, we present EL spectra at various $\mathrm{cw}$ injection currents at $150 \mathrm{~K}$ for the $l=1500-\mu \mathrm{m}$-long device (Fig. 2). At a current density of $J$ $=160 \mathrm{~A} / \mathrm{cm}^{2}$ threshold for the GS transition is reached, peaked at $1212 \mathrm{~nm}$. Due to the higher gain at low temperature, GS lasing occurs first, but as the current injection is further increased up to $J=360 \mathrm{~A} / \mathrm{cm}^{2}$, ES lasing proceeds nevertheless at a wavelength of $1150 \mathrm{~nm}$. Obviously, gain clamping does not occur for the ES once the GS has reached threshold. Moreover, the lasing modes at threshold of both state transitions appear at the peak positions of the inhomogeneously broadened spontaneous emission curves. This suggests two-state lasing of the same dot family within the QD ensemble, corresponding to a dot geometry with the highest density.

In order to gather further insight into the lasing mechanism, we measured the spectrally resolved light-current characteristcs for different lengths. Figure 3 shows the integrated GS peak, the integrated ES peak, and the total area of EL spectra of 1650- and 2000- $\mu \mathrm{m}$-long devices versus the current density at room temperature. The current was injected in $1-\mu$ s pulses with $1 \%$ duty cycle, to minimize heating effects. In the 1650- $\mu$ m-long cavity [Fig. 3(a)], GS lasing occurs at $J=300 \mathrm{~A} / \mathrm{cm}^{2}$ and ES lasing starts at $J$ $=1140 \mathrm{~A} / \mathrm{cm}^{2}$. Once the threshold of the ES transition is reached, the integrated intensity of the GS peak saturates and then becomes increasingly suppressed, leading to a rising slope of the ES line. For the 2000- $\mu$ m-long device [Fig. $3(\mathrm{~b})]$, the GS threshold current density is slightly lower $(J$ Downloaded 07 Jan 2008 to 131.155.108.71. Redistribution subject

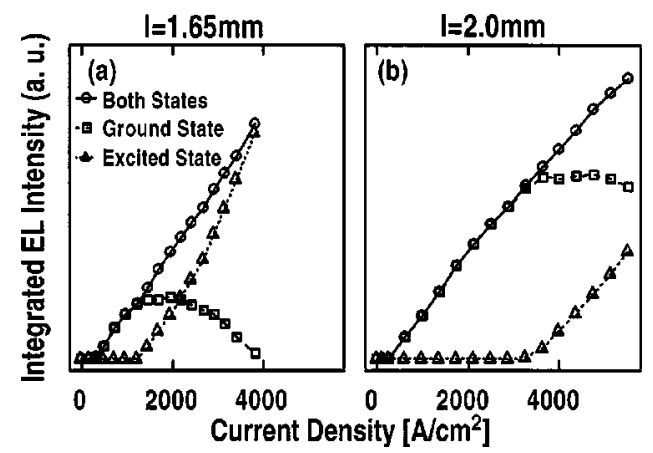

FIG. 3. Integrated areas of GS peak, ES peak, and both peaks of the EL spectra (room temperature, pulsed excitation) of a (a) $1650-\mu \mathrm{m}$ and (b) 2000- $\mu \mathrm{m}$-long cavity in dependence of the current density.

$=240 \mathrm{~A} / \mathrm{cm}^{2}$ ), whereas the ES threshold current density is much larger $\left(J=3190 \mathrm{~A} / \mathrm{cm}^{2}\right)$. We note that the slope of the total light-current curve does not change at the ES threshold, showing that the GS and ES transitions compete for the same carriers.

Experimental evidence for two seperate lasing peaks in the EL spectrum was also found by other authors, ${ }^{12,13}$ although in those reports it was unclear whether the two lines were related to two different states, due to a large spectral overlap of their inhomogeneous broadening. On the other hand, the possibility of two-state lasing in theory was already mentioned by Grundmann et al. ${ }^{14}$ in the framework of the master-equation model of QD microstates. ${ }^{14,15}$ In the following we apply a similar approach: In each QD we assume a twofold degenerate GS level and a fourfold degenerate ES level. The QDs are filled with excitons from the barrier into the ES within $10 \mathrm{ps}$, consistent with our measurements. ${ }^{16}$ Hole relaxation from the ES to the GS is assumed to be infinitely fast, while the electron relaxation time $\tau_{0}$ was used as the only fitting parameter, yielding $\tau_{0}=7$ ps as a best fit. A thermal escape time from the GS to the ES and from the ES to the barrier has been included, by assuming the system reaches thermal equilibrium in the absence of external excitation. The radiative lifetime $\tau_{r}$ for electrons in the GS was measured $^{17}$ to be around $1 \mathrm{~ns}$ and is set to be identical for electrons in both levels. The internal losses were experimentally determined to be $2 \mathrm{~cm}^{-1}$, and the Einstein $B$-factor was chosen so to provide a minimum device length of $1500 \mu \mathrm{m}$ for GS lasing, consistent with the experiment.

The calculated results of the photon number in the cavity versus injection current (in units of number of carriers injected per lifetime per dot) from a 1650- and a 2000- $\mu$ mlong device are shown in Figs. 4(a) and 4(b), respectively. In both cases, once the threshold of ES lasing is reached, the slope of the GS line becomes drastically reduced and the ES line increases linearly. A similar behavior is observed in the experimental results in Fig. 3, with a stronger suppression of the GS line and an increasing slope of the ES line.

An intuitive picture of the double-state lasing process is provided by Figs. 4(c) and 4(d), which depict the respective average populations of GS and ES. Above the GS lasing threshold, the GS population is pinned to its value: every carrier added to the GS is quickly recombined via stimulated emission of a photon with the GS transition energy. The increasing stimulated emission rate from the GS requires an to AIP license or copyright; see http://apl.aip.org/apl/copyright.jsp 


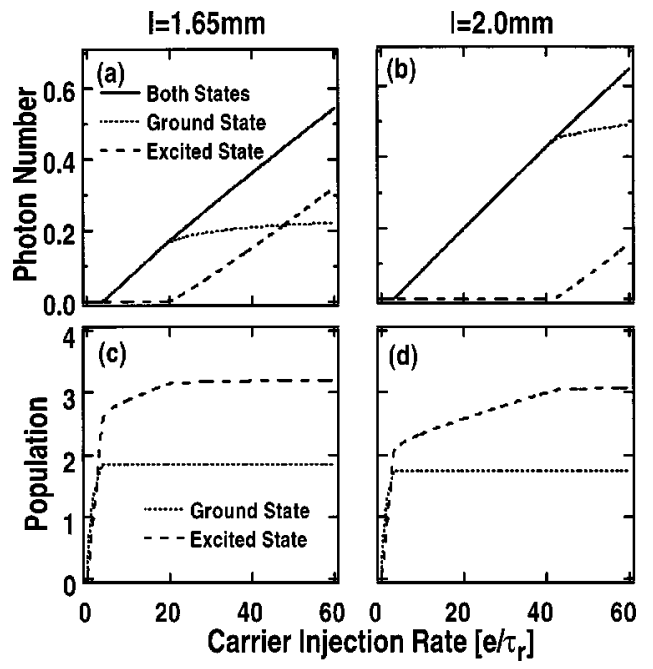

FIG. 4. Theoretical calculation within a master-equation model of the photon number and the average energy level population in a cavity with a length of (a), (c) $1650 \mu \mathrm{m}$ and (b), (d) $2000 \mu \mathrm{m}$ as a function of the injection current.

increasing relaxation rate from the ES to the GS, which implies a larger ES population because of the finite relaxation time. Consequently, the number of carriers in the ES keeps increasing, although at a lower rate. The situation changes when ES lasing threshold is reached and its population clamps, as well: now, the injected carriers entertain two lasing modes. In this scenario, the stimulated emission from the ES competes with the relaxation to the GS, which highly favors ES lasing. The ratio of ES and GS threshold currents depends strongly on the cavity length (hence on the threshold gain), as shown in Fig. 5. The experimental results [Fig. 5, dots] are well reproduced by our model [Fig. 5, line]. This correspondence is remarkable, considering that the only fitting parameter is the relaxation time $\left(\tau_{0}=7 \mathrm{ps}\right)$.

Note that the slope of the ES population above GS threshold [Figs. 4(c) and 4(d)] is determined by the relaxation mechanism only. Its impact depends on the relaxation

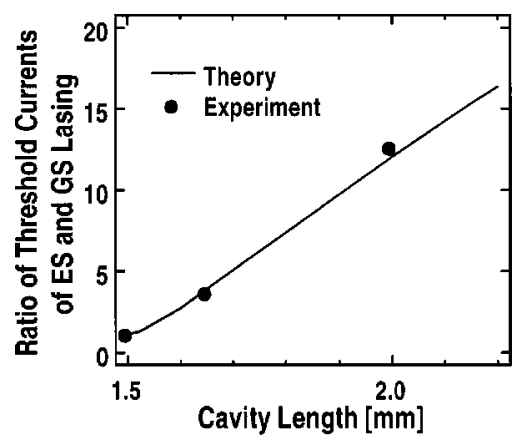

FIG. 5. Comparison of experimental and theoretical ratio between ES and GS threshold currents at different cavity lengths. time $\tau_{0}$, but also on the availability of GS levels: when the GS is almost filled, the relaxation from the ES is inhibited. In shorter cavities with a higher GS population above threshold, the relaxation probability is lower and the ES population increases at a higher rate. In other words, the phononbottleneck effect becomes significant as the number of available states for the relaxation is reduced. In a system with a large density of available states at the lower energy level, such as a QW, lasing on the ES would not be achieved in practice.

In summary, we demonstrated simultaneous two-state lasing in QD lasers and quantitatively understood this behavior within a master-equation model. We identified the finite relaxation time in QDs as the origin of that effect, which becomes a crucial parameter at a high population of the GS level. These results imply that, in order to avoid saturation of GS lasing power, QD lasers should be operated at threshold gain values much lower than the saturated GS gain.

This work was supported by the European Commission (EC) under the Information Societies Technology "Gallium Arsenide Second Window Quantum Dot Lasers (GSQ)" project and the Swiss National Science Foundation.

${ }^{1}$ M. Grundmann, Physica E (Amsterdam) 5, 167 (2000).

${ }^{2}$ G. Park, O. B. Shchekin, D. L. Huffaker, and D. G. Deppe, IEEE Photonics Technol. Lett. 10, 230 (2000).

${ }^{3}$ O. B. Shchekin and D. G. Deppe, Appl. Phys. Lett. 80, 3277 (2002).

${ }^{4}$ P. Bhattacharya and S. Ghosh, Appl. Phys. Lett. 80, 3482 (2002).

${ }^{5}$ H. Saito, K. Nishi, A. Kamei, and S. Sugou, IEEE Photonics Technol. Lett. 12, 1298 (2000).

${ }^{6}$ H. Benisty, C. M. Sotomayor-Torrès, and C. Weisbuch, Phys. Rev. B 44, 10945 (1991).

${ }^{7}$ M. Sugawara, K. Mukai, and H. Shoji, Appl. Phys. Lett. 71, 2791 (1997).

${ }^{8}$ J. X. Chen, U. Oesterle, A. Fiore, R. P. Stanley, M. Ilegems, and T. Todaro, Appl. Phys. Lett. 79, 3681 (2001).

${ }^{9}$ J. X. Chen, A. Markus, A. Fiore, U. Oesterle, R. P. Stanley, J. F. Carlin, R. Houdre, M. Ilegems, L. Lazzarini, L. Nasi, M. T. Todaro, E. Piscopiello, R. Cingolani, J. Katcki, and J. Ratajczak, J. Appl. Phys. 91, 6710 (2002).

${ }^{10}$ M. V. Maximov, L. V. Asyran, Yu. M. Shernyakov, I. N. Kaiander, V. V. Nikolaev, A. R. Kovsh, A. F. Tsatsul'nikov, B. V. Volovik, D. A. Bedarev, A. E. Zhukov, A. R. Kovsh, S. S. Mikhrin, V. M. Ustinov, A. E. Zhukov, Zh. I. Alferov, N. N. Ledentsov, and D. Bimberg, IEEE J. Quantum Electron. 37, 676 (2001)

${ }^{11}$ L. V. Asryan, M. Grundmann, N. N. Ledentsov, O. Stier, R. A. Suris, and D. Bimberg, IEEE J. Quantum Electron. 37, 418 (2001).

${ }^{12}$ D. Bhattacharya, E. A. Avrutin, A. C. Bryce, J. H. Marsh, D. Bimberg, F. Heinrichsdorff, V. M. Ustinov, S. V. Zaitsev, N. N. Ledentsov, P. S. Kopev, Zh. I. Alferov, A. I. Onischenko, and E. P. OReilly, IEEE J. Sel. Top. Quantum Electron. 5, 648 (1999).

${ }^{13}$ P. M. Smowton, E. J. Johnston, S. V. Dewar, P. J. Hulyer, H. D. Summers, A. Patanè, A. Polimeni, and M. Henini, Appl. Phys. Lett. 75, 2169 (1999).

${ }^{14}$ M. Grundmann, A. Weber, K. Goede, V. M. Ustinov, A. E. Zhukov, N. N. Ledentsov, P. S. Kopev, and Zh. I. Alferov, Appl. Phys. Lett. 77, 4 (2000).

${ }^{15}$ M. Grundmann and D. Bimberg, Phys. Rev. B 55, 9740 (1997).

${ }^{16}$ A. Fiore, P. Borri, W. Langbein, J. M. Hvam, M. Cantoni, F. Bobard, U. Oesterle, R. Houdré, R. P. Stanley, F. Lelarge, and M. Ilegems, IEEE J. Quantum Electron. 37, 1050 (2001).

${ }^{17}$ A. Markus, A. Fiore, J. D. Ganière, U. Oesterle, J. Chen, B. Deveaud, M. Ilegems, and H. Riechert, Appl. Phys. Lett. 80, 911 (2002). 